\title{
The determination of field usability of method measuring temperature fields in the air using an infrared camera
}

\author{
Martin Pešek ${ }^{1, a}$ and Ondřej Pech ${ }^{1}$ \\ ${ }^{1}$ Brno University of Technology, Faculty of Mechanical Engineering, Technická 2896/2, Czech Republic
}

\begin{abstract}
The article deals with the field usability determination of the method for measuring temperature fields in the air using an infrared camera. This method is based on the visualization of temperature fields on an auxiliary material, which is inserted into the non-isothermal air flow. In this article the field usability is determined from time constants of this method, which define borders of usability for low temperature differences (between air flow temperature and surrounding temperature) and for low air flow velocities. The field usability determination for measuring temperature fields in the air can be used in many various applications such as air-heating and air-conditioning where the method of measuring temperature fields in the air by infrared camera can be used.
\end{abstract}

\section{Introduction}

The temperature field measurement by the infrared camera is very illustrative and quick way to measure the value of temperature or the temperature field. The infrared camera allows for noncontact measurement and it is used for this purpose in many scientific disciplines and industrial applications, especially in the field of heat transfer and thermodynamics [1]. The thermography is mainly used for the surface temperature measurements. The auxiliary materials application for monitoring temperature fields the air temperature field is known a long time [2]. This measuring method provides visual image records providing qualitative and quantitative information for deeper knowledge of thermal conditions and thermodynamic processes in the research object. The infrared camera allows measurements of the static conditions and monitoring of dynamic processes and it is very suitable for the usage outside the laboratory. The important issue is to define the most suitable materials that can be used for monitoring of the temperature distribution in the air using infrared camera by the method of inserting a sheet of paper or other auxiliary material into the non-isothermal airstream. This material must have suitable static properties, mainly a high emissivity. Also, knowledge of the dynamic properties, especially the knowledge of the time constant as a function of air temperature difference and the air velocity is required for practical applications of the method. The temperature visualization by the infrared camera also allows for the deeper understanding and identifying of connections in the measuring processes during the monitoring of a variable temperature field. The visualization of temperature fields in the air can also detect the spatial and time context of monitored processes. This method for the measurement of temperature fields in the air can be used in many fields of heating and cooling [2].

\section{The measuring method description}

The measurement method of temperature fields is based on the usage of the auxiliary material on which the temperature fields are displayed. This auxiliary material is placed to the air-stream of monitored area [3]. The convective heat flow changes the surface temperature of auxiliary material which is measured by the infrared camera. The conduction heat flow creates the temperature field on surface of the auxiliary material and this surface temperature can be considered as the air temperature of this area.

\section{Conduction heat transfer}

During the visualization of the air temperature field on the surface of the auxiliary material, conduction heat transfer occurs the distribution and also the temperature field scattering in the sheet of this material. The heat transfer by conduction is defined by the Fourier's law as

$$
\dot{q}=-\lambda \cdot \operatorname{grad} T,
$$

where $\dot{q}\left(\mathrm{~W} \mathrm{~m}^{-2}\right)$ is the conduction heat flux, $\lambda\left(\mathrm{W} \mathrm{m}^{-1} \mathrm{~K}^{-1}\right)$ is the heat conductivity and $\operatorname{grad} T\left(\mathrm{~K} \mathrm{~m}^{-1}\right)$ is the temperature gradient.

\footnotetext{
${ }^{\mathrm{a}}$ Corresponding author: m.pesek@email.cz
} 
The temperature field scattering causes the enlargement of the area with the visualized air flow, and therefore it also causes a shift of the air flow boundary. Conduction heat transfer is not desired and is requested to be eliminated by the use of an auxiliary material with a low value of the heat conductivity. Unfortunately, the low value of heat conductivity means very difficult heat transfer by convection on the surface of auxiliary material. Low heat conductivity causes problems with imagining of dynamic processes.

Borders enlargement of the non-isothermal airstream is possible to determine as a solution of heat conduction problem in a semi-infinite body. Semi-infinite body represents the body where exists a certain distance $x_{0}$ from the surface such that for all the distances $x>x_{0}$ the temperature $T(x, t)$ equals the initial temperature $T_{0}(x, t=0)$ even though a change of the temperature occurs at the surface $(x=0)$. This means that the surface temperature can influence the temperature inside the body up to the distance $x$ from the surface.

\section{Convective heat transfer}

For the determination of heat transfer from the air stream to the material it is necessary to define heat transfer by convection. The convective heat flow $\dot{q}\left(\mathrm{~W} \mathrm{~m}^{-2}\right)$ is determined by the Newton's law

$$
\dot{q}=\alpha \cdot\left(T-T_{\infty}\right)
$$

where $\alpha\left(\mathrm{W} \mathrm{m}^{-2} \mathrm{~K}^{-1}\right)$ is the heat transfer coefficient, $T(\mathrm{~K})$ is surface temperature and $T_{\infty}(\mathrm{K})$ is free stream temperature.

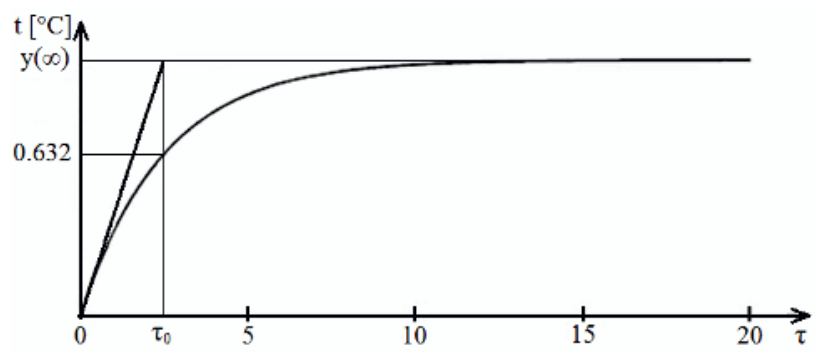

Figure 1. Approximation with the use of the proportional system of the first order [4]

The time constant $\tau_{0}(s)$ is the quantity which characterizes the time needed for the transitional state (caused by an input impulse) to arise or disappear. The time constant is defined as the time when $63.2 \%$ of all increase or decrease value of monitoring quantity is reached, figure 1 .

\section{Measurements of the temperature field scattered in the auxiliary material}

The heat conduction, which cases the expansion of the temperature field area in the auxiliary material, was investigated as well. The assessment of the conduction heat transfer effect was performed by an experiment and also by numerical simulation in STAR $\mathrm{CCM}+$ software program. Two types of auxiliary materials with high emissivity values were investigated. A common sheet of office paper with the emissivity 0.96 and a sheet of cotton textile with the emissivity 0.93 were considered.

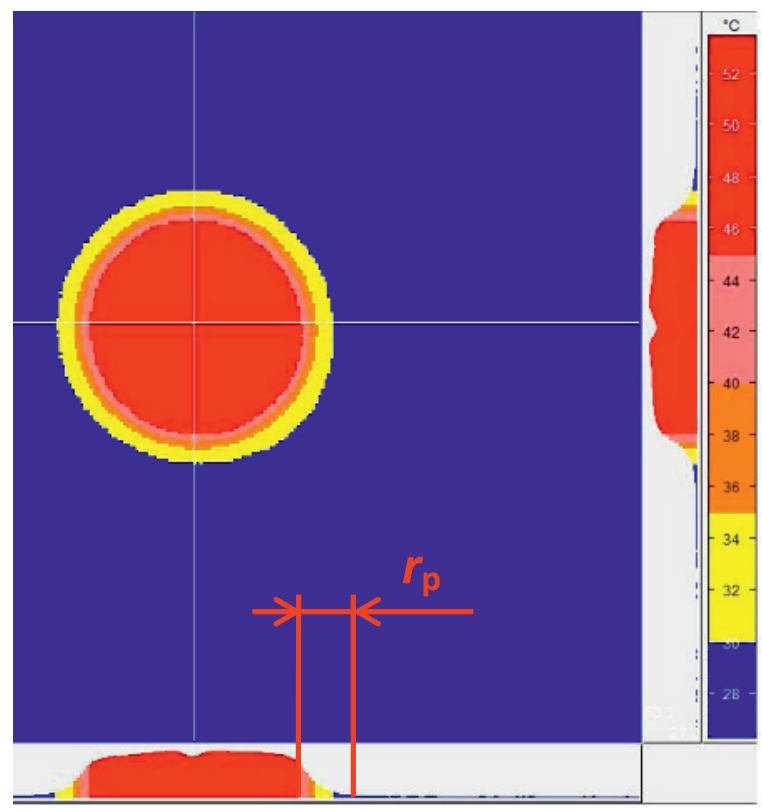

Figure 2. Evaluation of experiment the temperature field scattered in a sheet of paper at steady state which occurred after 10 seconds

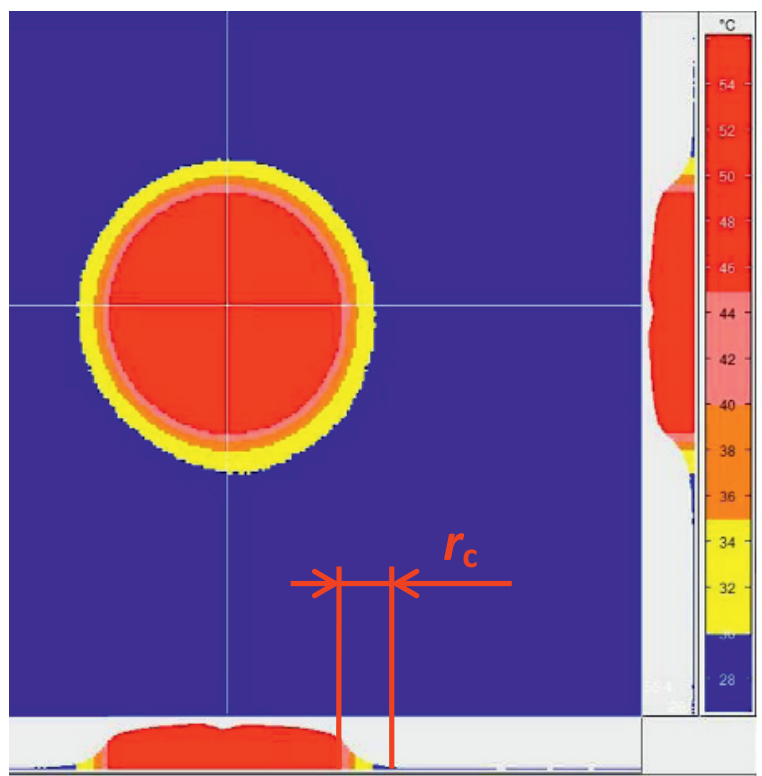

Figure 3. Evaluation of experiment the temperature field scattered in a cotton sheet at steady state which occurred after 10 seconds

The experimental determination of temperature field scattering was performed with the use of the thermal print with known dimensions. Subsequently time courses of expansion of the temperature field in the sheet of auxiliary material were recorded. The object used as the thermal print was selected to be a cylinder which was made from stainless steel (stainless steel 304) with the diameter $d=50 \mathrm{~mm}$ and height $h=80 \mathrm{~mm}$. 
The experiment was performed with the use of the infrared camera Jenoptic VarioCam. The cylinder was attached to the holder and conductively heated to approximately $50{ }^{\circ} \mathrm{C}$. Then the sheet of the auxiliary material was shortly pressed at the base of the cylinder and the infrared sequence in $60 \mathrm{~s}$ was recorded. The infrared record evaluation was carried out in the IRBIS professional software program. After the contact of the thermal print with the sheet of auxiliary material it immediately extended the temperature field outside the edge of the cylinder by the value of $r_{\mathrm{c}}$ for the cotton sheet or by the value of $r_{\mathrm{p}}$ for paper sheet. The temperature field was stabilized after $10 \mathrm{~s}$ for printing to the cotton sheet and also to the paper sheet. Using the command "reference line" in the IRBIS professional software the size of the temperature field expansion was determined. In case of the cotton sheet the scattering is $r_{\mathrm{c}}=3.5 \mathrm{~mm}$ and in case of a paper sheet $r_{\mathrm{p}}=3.9 \mathrm{~mm}$. The evaluations of these sheets are shown in figure 2 and 3 . The scattering size area was measured from the edge of the thermal print to the distance where the temperature fell to $5 \%$ of the total temperature difference.

Table 1. Static properties table of auxiliary materials to determine the temperature field scattering

\begin{tabular}{|c|c|c|c|}
\hline $\begin{array}{l}\text { Auxiliary } \\
\text { materials } \\
\text { properties }\end{array}$ & $\begin{array}{l}\text { Office } \\
\text { paper }\end{array}$ & $\begin{array}{l}\text { Cotton } \\
\text { fabric }\end{array}$ & $\begin{array}{c}\text { Thermal } \\
\text { print }\end{array}$ \\
\hline $\begin{array}{c}\text { mass per area } \\
m,\left(\mathrm{~g} \mathrm{~m}^{-2}\right)\end{array}$ & 80 & 145 & - \\
\hline $\begin{array}{c}\text { emissivity } \\
\varepsilon,(-) \\
\end{array}$ & 0.96 & 0.93 & - \\
\hline $\begin{array}{c}\text { density } \\
\rho,\left(\mathrm{kg} \mathrm{m}^{-3}\right)\end{array}$ & 750 & 1550 & 8000 \\
\hline $\begin{array}{c}\text { specific heat } \\
\text { capacity } \\
c,\left(\mathrm{~J} \mathrm{~kg}^{-1} \mathrm{~K}^{-1}\right)\end{array}$ & 1330 & 1160 & 500 \\
\hline $\begin{array}{c}\text { heat } \\
\text { conductivity } \\
\lambda,\left(\mathrm{W} \mathrm{m}^{-1} \mathrm{~K}^{-1}\right)\end{array}$ & 0.05 & 0.029 & 16.2 \\
\hline
\end{tabular}

The investigated heat conduction problem in the auxiliary material was also investigated by numerical simulations.

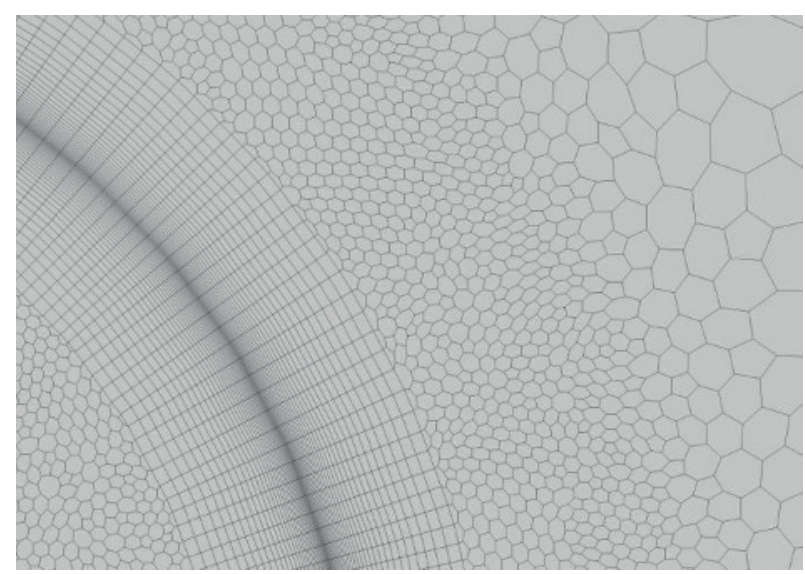

Figure 4. Simplified geometry of the model for the determination of the temperature field scattered in the sheet of auxiliary material
One of possible simulation programs is STAR CCM+. This program allows to solve non-stationary heat conduction problems. The first step was to create the model geometry. In this geometry model is subsequently applied mathematical techniques and physical laws on the based on defined boundaries and initial conditions. The static properties of auxiliary materials were used according to table 1 , i.e. the same conditions as were in the experiment. The simulation was performed on the simplified model, see figure 4.

The model was created with a 2D polyhedral computational grid with a density of 36,000 cells. Due to a better description of heat transfer into the sheet of auxiliary material, the thermal print position and the measured sheet were equipped with a prismatic boundary layer with a thickness of 30 cells $(4 \mathrm{~mm})$. The area where the distribution of temperature field was expected from the experiment $(10 \mathrm{~mm}$ from the wall of cylinder to the material), was refined in order to achieve a more accurate description of the distribution of the heat flow into the auxiliary material.

At the border the boundary condition was set to "Symmetry plane". The "Symmetry plane" boundary condition does not limit the calculation and it will not influence the undesired heat energy accumulation at the borders of geometry. In the position of the contact thermal print material, the "in-place" boundary condition was introduced, which allows the contact between two different kinds of materials (thermal print and sheet of an auxiliary material).

The simulation was solved as a non-stationary task lasting 30 seconds, which leads to two material prints of different temperatures with a constant density. Due to the ease of calculation, the segregated solver involving secondary solid energy gradients was chosen. During the calculation the monitoring of the residual energy convergence level with the accuracy higher than $10^{-4}$ was carried out. The result of the mathematical simulation from the simulation program STAR CCM+ is shown in figures 5 for sheet of office paper. For the cotton sheet the values $r_{c}=3.2 \mathrm{~mm}$ was calculated and for the paper sheet it was $r_{p}=3.8 \mathrm{~mm}$, which is in agreement with experiments.

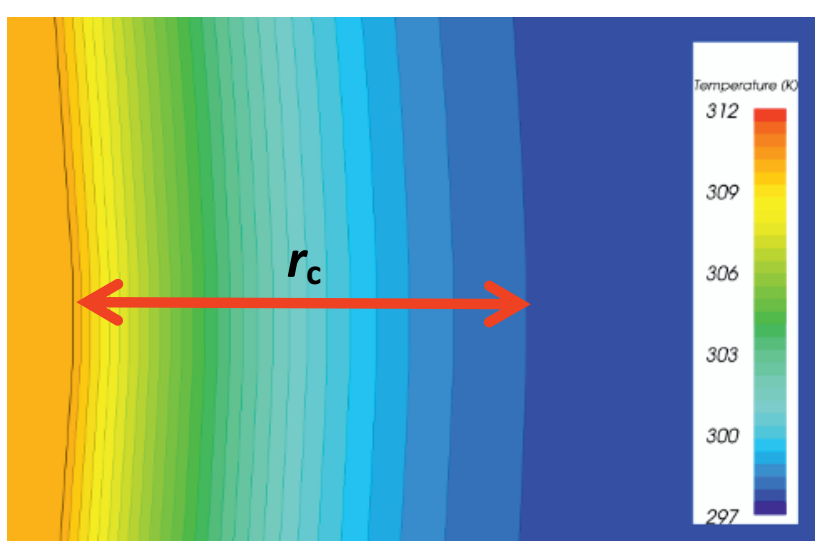

Figure 5. Evaluation of mathematical simulation of the temperature field scattered in a sheet of paper at steady state after 10 seconds 


\section{Determination of field usability}

Measurements of the air temperature field using the investigated method is relatively accurate, if they are done in the field of usability of the method. The area of field usability is based on limiting the range of the temperature difference and the range of the velocity nonisothermal air flow, which depend on the time constant of the method. The measurement accuracy is determined by measurement uncertainties $[4,5]$. In areas where a high uncertainty is produced, it is not appropriate to measure the temperature field using this method.

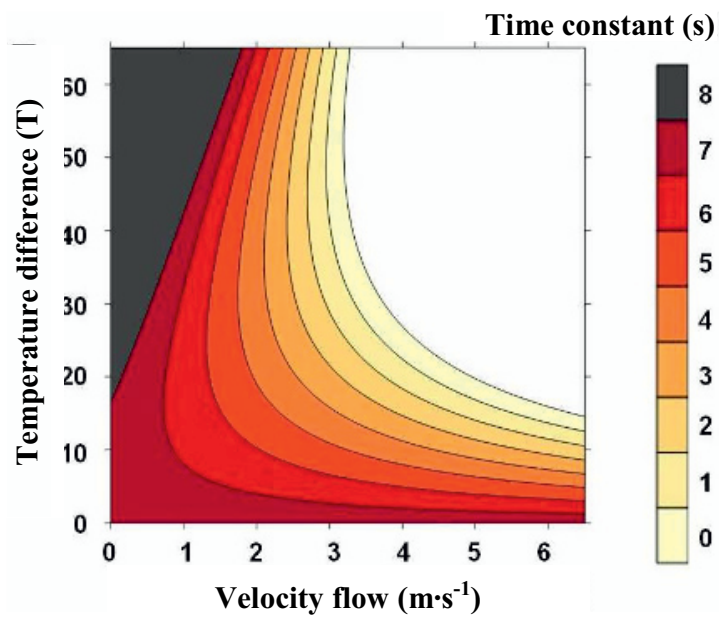

Figure 6. 2D view on the field of usability of the method for the visualization and measurement of temperature fields in air by infrared camera - the office paper

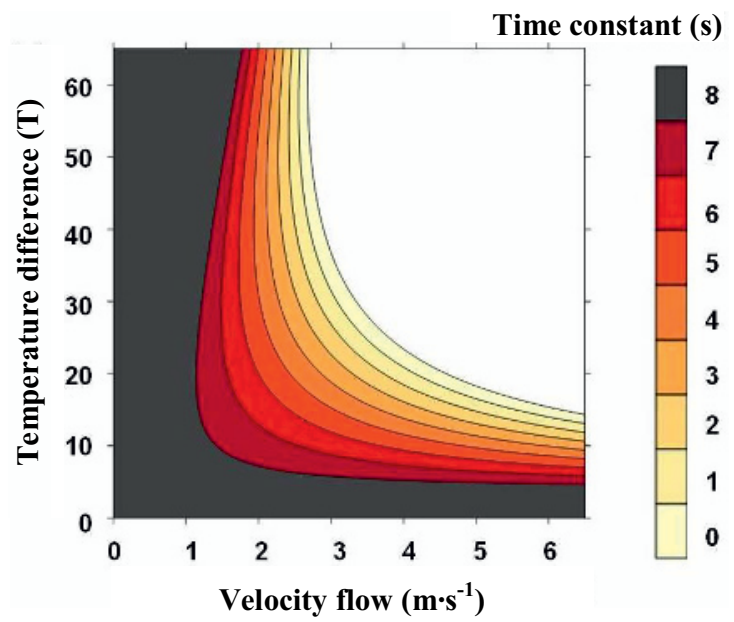

Figure 7. 2D view on the field of usability of the method for the visualization and measurement of temperature fields in air by infrared camera - the cotton sheet

The field of usability of the method was determined from the dependence on the time constant, temperature differences and flow velocity for the cotton textile and for the office paper In these dependences (Figure 6 and 7) the area with a high time constant was suppressed, which indicates that the temperature field measurement using this method is less suitable in these areas.

\section{Conclusions}

The obtained graphs of the time constants are important for creating a methodology for measurements of temperature fields in the air by the infrared camera. The time constants with the emissivity of auxiliary material, parameters of infrared camera and application limits of the described method allow for measurements in case of low velocities and small temperature differences.

The field of usability of the infrared camera for measurements of the temperature field in the air is related to requirements, which are required by applications or measurements. In the case the time constant of the method is required to be less than 8 seconds, the field usability can be determined from figure 8 and figure 9 . These values for the time constant of $8 \mathrm{~s}$ are included in table 2 .

Table 2 Field usability of the method for visualization and measurement of temperature fields in air using an infrared camera for the time constant less than 8 seconds

\begin{tabular}{|c|c|c|}
\hline Auxiliary material & Velocity & $\begin{array}{c}\text { Temperature } \\
\text { difference }\end{array}$ \\
\hline office paper & $\begin{array}{c}\text { depends on } \\
\text { the IR } \\
\text { camera } \\
\text { accuracy }\end{array}$ & $\begin{array}{c}\text { depends on the } \\
\text { IR camera } \\
\text { accuracy }\end{array}$ \\
\hline cotton sheet & $\begin{array}{c}\text { from } \\
1.2 \mathrm{~m} \mathrm{~s}^{-1}\end{array}$ & from $6 \mathrm{~K}$ \\
\hline
\end{tabular}

In assessing of the field usability of the method it is necessary to consider the influence of heat conduction in the auxiliary material. This can cause some "blur" effects which is usually not possible to identify in nonisothermal air streams. This effect needs to be especially considered in areas with large temperature gradients, e.g. in thermal limit layers.

\section{Acknowledgements}

The research leading to the presented results was supported by the NETME Centre ED0002/01/01 and Brno University of Technology project FSI-J-13-2042 for young researchers.

\section{References}

1. M. Vollmer, K.-S. Mollmann, Infrared Thermal Imaging: Fundamentals, Research and Applications, Wiley (2010)

2. M. Pešek, M. Pavelek, Setkání kateder mechaniky tekutin a termomechaniky, Mikulov (2010)

3. M. Pešek, M. Pavelek, Experimental fluid mechanics, Jičín (2011)

4. T. Orzechowski, Ł.J. Orman, Science Report (2006)

5. T. Orzechowski, Ł.J. Orman, Pollution Engineering (2006) 